\title{
La sostenibilidad cultural: El reconocimiento del tango como patrimonio de la humanidad
}

Marta Rosalía Norese ${ }^{(1)}$

Resumen: Sostenibilidad cultural. El tango ya tiene entre 130 y 140 años desde su creación por 'la gente pobre de los conventillos montevideanos y porteños, que fueron los inventores del tango". La hibridez de ese pueblo -mezclas infinitas de inmigración externa e interna- lo impulsa a reaccionar ante las crisis y los golpes de la vida, crea una dinámica, desarrolla una habilidad y consigue (al menos siempre lo intenta) que las crisis sean creativas. Argentina tuvo desde el siglo XIX educación laica libre y para todos. La ciudad pudo tener hambre o dificultades pero tuvo un pueblo con inteligencia y creatividad. Por eso el tango surge y vive y sobrevive. No es siempre el mismo tango: la realidad cambia, cambia la gente, cambia la felicidad y el dolor. Pero siempre hay una respuesta... y por tanto un renacer. Capaz de inventarse una lengua: el lunfardo, y una música: El tango. Pueblo mestizo y heterodoxo, que crece con las crisis, expresándose con su cultura.

Palabras claves: Tango - inmigración fin s.XIX - renacer tango 1990 - lunfardo - milongas - Patrimonio Cultural inmaterial - ortodoxia-heterodoxia.

[Resúmenes en inglés y portugués en las páginas 118-119]

(1) Doctora en Ciencias de la Música y Máster en Educación por la Universidad de Salamanca, España. Académica Correspondiente de la Academia Nacional del Tango de la República Argentina, año 2009. Musicóloga, Profesora Superior de Música (guitarrista) en Buenos Aires, Argentina.

\section{Introducción. Declaración del Comité Intergubernamental de la Unesco}

Eran alrededor de las 8 de la mañana del 29 de setiembre de 2009, cuando se anunció, con lo que sería el primer aplauso de la sesión, que: "Argentina y Uruguay han postulado como patrimonio cultural al tango, un género musical que incluye danza, música, poesía y canto, y que es considerado una de las principales manifestaciones de identidad para los habitantes de la región del Río de la Plata", recordaron las autoridades del comité Intergubernamental de las Naciones Unidas que se realizó en los Emiratos Árabes. "No veo ninguna objeción. Queda aprobado", sentenció Awad Ali Saleh Al Musabi, el emiratí que lo presi- 
día, ante los ojos de la prensa de todo el globo. En las delegaciones argentina y uruguaya, que habían propuesto al tango hacía exactamente un año, hubo lágrimas. Eduardo Duter, el director de cultura montevideano, leyó un agradecimiento conjunto: "En este momento, una paica (mujer) y un milonguero se estrechan en un firulete (paso de baile de tango)", dijo, ocasionándole algunas dificultades a los atribulados traductores en simultáneo.

El ministro de Cultura porteño, Hernán Lombardi, que dicen que por los nervios no pudo dormir en toda la noche, recordó la Milonga de los orientales, de Jorge Luis Borges": "Milonga (baile argentino que fue uno de los precursores del tango) para que el tiempo/ vaya borrando fronteras; /por algo tienen los mismos / colores las dos banderas (de Argentina y Uruguay)", recitó.

Con ellos estaba el embajador argentino en la Unesco, el pianista Miguel Ángel Estrella, que después confesó su emoción "como argentino, como hombre que ama al Uruguay y como músico. Este es un homenaje tardío para aquella gente muy pobre de los conventillos (casas muy pobres de alquiler) montevideanos y porteños, que fueron los inventores del tango".

En La Nacion, periódico argentino, el 20 enero de $2009^{2}$, con una extensa nota, informaban de la presentación entre Uruguay y Argentina, del pedido de declaración como Patrimonio inmaterial de la Humanidad al tango. Importante la síntesis que acompañaban: - Qué significa para el tango: la declaración de Unesco agrega al tango un valor simbólico y una seña de identidad local. Involucra a todos los actores y todos los elementos que interactúan en su existencia.

- Patrimonio inmaterial: son las tradiciones y expresiones orales, artes de espectáculo, usos sociales, rituales y actos festivos, entre otros.

- Compromiso: Buenos Aires y Montevideo se comprometen, entre otras acciones, a crear un Centro de Documentación y Registro del Tango; a recuperar manuscritos, material sonoro, vestuario de época e instrumentos musicales. Además, se creará un Instituto de enseñanza del tango-danza y una cátedra del bandoneón.

"El tango, patrimonio de la humanidad" Es el titular del BBC -Mundo del 30 de septiembre de 2009. ${ }^{3}$

Cerca de 400 expertos de la Unesco decidieron en Abu Dhabi que el Tango ese "baile seductor con letra melancólica debe ser salvaguardado". Este baile "personifica y alienta tanto la diversidad cultural como el diálogo", informó la organización.

"Entre esta mezcla de inmigrantes europeos, descendientes de esclavos y criollos surgió un amplia gama de costumbres, creencias y rituales que se transformó en un distintivo cultural de identidad", fundamentó la Unesco su decisión dice el periódico.

Ese dictamen tiene en cuenta cuatro rasgos que lo distinguen: 1) Es distinto, 2) original, 3) las comunidades rioplatenses lo sienten como propio, 4) enriquece el acerbo cultural y existe un plan conjunto de preservación.

Este plan conjunto fue presentado por los gobiernos locales de Montevideo y Buenos Aires un año antes de la distinción, cuando inscribieron el tango ante la Unesco.

"Nos comprometimos a realizar conferencias, seminarios y talleres, así como iniciar un proyecto de preservación de partituras que rescate toda la tradición oral", le dijo a BBC Mundo Hernán Lombardi, ministro de Cultura del gobierno de Buenos Aires. 
El Ministro Lombardi, en 2009 también explicó que, junto con Montevideo, pensaron fundar una orquesta de tango rioplatense. La distinción no significa un aporte económico, pero según Lombardi "La Unesco te da la distinción que significa un compromiso".

En los periódicos argentinos ${ }^{4}$ Clarín, Página 12, Perfil, La Capital de Mar del Plata (que señala" En la reunión de la Unesco se presentaron 111 candidaturas, de las cuales quedaron 76 para su consideración, y "El tango" fue la primera en tratarse, ser votada y aprobada.") del 30 de setiembre de 2009 aparece como gran titular: "El Tango fue declarado patrimonio cultural inmaterial de la humanidad".

"La Unesco declaró hoy al tango Patrimonio Cultural Inmaterial de la Humanidad. Durante la cuarta reunión de expertos del Comité Intergubernamental que se realizó en los Emiratos Árabes. Para festejar se realizará un Gran Milonga Abierta el sábado y el domingo en San Juan y Boedo (un cruce de calles muy típicas de la periferia de la ciudad de Buenos Aires)."

En este periódico se aclara que: "La declaración para la salvaguardia del patrimonio cultural inmaterial del género (en este caso El Tango) se dio a conocer hoy ante la presencia de 400 delegados de todo el mundo reunidos en los Emiratos Árabes. El documento había sido presentado ante la Unesco en octubre de 2008 e incluido para su evaluación, mientras que en marzo último pasó la aprobación de los expertos externos."

El souvenir.com, de México, con el título de Patrimonio Unesco, Tango, Patrimonio inmaterial de la Humanidad, recuerda la designación diciendo: "El tango es el baile del amor, la pasión, el erotismo y la complicidad. Encontrar un compañero de baile es un compromiso para toda la vida. Es saber que el otro siente, ríe y sufre tanto o más que nosotros.

De un lado a otro del salón se miran, él cabecea ligeramente hacia la pista invitándola a bailar, ella toma un par de segundos y decide aceptar. Y así con una mirada empieza el juego...

El tango... es el lazo que une a la pareja que lo baila, entra por sus oídos llega a sus músculos y los domina, sabe del amor, la traición, la pasión pero sobre todo del dolor."

Son visiones casi todas literarias, poéticas, que nos hablan de sentimientos, amor y dolor, pero también de compañía, empatía, unión, en sus tres vertientes de poesía, música y danza. Que no son modas sino esencias humanas que llevan a la necesidad del contacto, de entenderse, de expresarse. Alguien alguna vez me dijo que el tango triunfaba porque en un mundo frio y desangelado era la única manifestación que necesitaba y usaba 'el abrazo'. ${ }^{5}$ José María Kokubu lo afirma en su participación en el II Congreso "Tango, Cultura e Identidad" que se hizo en setiembre de 2016 en Buenos Aires:

"El tango se ha extendido por todo el mundo: Nueva York, Karachi, Bogotá, París, Tokio, México, Auckland, Pekín Berlín, Estambul, Singapur... y la tendencia sigue en crecimiento. Esto nos hace pensar que el fenómeno, más allá de cualquier moda pasajera, está cimentado en una fortaleza sustancial con valor intrínseco propio, universal y excluyente: el tango está determinado lingüísticamente en sus tres aspectos, a saber: de poesía, música y danza. Semejante particularidad lo aleja cualitativamente de la danza clásica, la salsa, la lambada la tarantela, el vals vienés, la cueca o el rock and roll."6 


\title{
¿Qué es el tango?
}

Yo digo que el tango es producto de una ciudad. No de un país, sino de una realidad urbana, en sus comienzos. En su ya muy extensa vida ha concitado amores y odios, pero... no ha dejado insensible a nadie. Y ya mayor, con prepotencia de vida, se ha extendido a casi todo el mundo.

Cuando comencé mis estudios hace ya varios años, creyendo que había mucho escrito ya, me encontré que el tema tango, como dirían los jóvenes ahora, era 'viral'. Todos querían saber y escribir y se sigue haciendo y el producto era literatura, poesía, sueños y ensueños. Poca realidad, y poca autenticidad (e investigación).

Hablar del tango como música del pueblo trabajador es mucho menos vendible que afirmar románticamente que su origen estaba en los oscuros prostíbulos (donde estaba prohibido hacer música y bailar, además de que estos lugares tenían otra finalidad).

Que fue música prohibida...? cuando hallamos que las partituras que se encontraron ya a fines del siglo XIX perfectamente editadas lo estaban hechas para piano o violín. Editar partituras era difícil y caro, tener violín y mucho más piano no estaba al alcance de malandrines (bandidos) o gente pobre, sino de casas con alto poder adquisitivo.

Es producto de una ciudad... muy versátil, muy distinta, suma de decenas de nacionalidades y partes del planeta que enviaban inmigrantes para aliviar -o tratar de hacerlo- el hambre que tenía su gente.

Digo en mi Tesis ${ }^{7}$, pág. 15, "Desde la sociedad educada y poderosa el tango fue rechazado y vituperado muy duramente. Pero no hacía muchos años, todavía después de mediados de siglo XIX, que críticas parecidas había recibido el vals, esa danza 'enlazada' que permitía contactos indecentes. También los negros en sus reuniones danzaban y eran considerados 'obscenos e inmundos'. Todo lo que no era 'como debía ser' recibía el anatema de una sociedad pacata y muy crítica. O muy pueblerina."

Es que los 'dueños del poder y de la tierra' no soportan que un sector de la sociedad que no era (y no lo es ahora) la poseedora de la cultura y el poder dominante, los inmigrantes internos y externos, pobres e incultos que tenían la osadía de crear una lengua para expresarse -el lunfardo-, una música, una poesía y una danza, que son capaces de llegar al poder en 1916 con Irigoyen, es más de lo que esos Señores pueden tolerar?

\author{
Enrique Maroni ${ }^{8}$, Antología Tanguera \\ Tango que me hiciste mal \\ y que, sin embargo, quiero... \\ porque sos el mensajero \\ del alma del arrabal;
}

Para terminar con:

el tango es como una garra

que se ha clavao en mi vida.

Me atrevo a traducirlo: Tango, que es la vida, y que como tal me ha hecho bien pero tam- 
bién mal, que me traes la voz de mi gente que es mi voz... es algo muy fuerte, querido y necesario, que es parte de mí.

\section{¿Cómo estudiar la realidad que genera el tango?}

Tenemos que conocer esa realidad que permite el nacimiento del tango, sus antecedentes, su historia y la realidad del momento de su creación. El fallo que ha permitido que se haga novela y no historia con respecto al tango es la falta de un contexto conocido y analizado que justifique su existencia, es la falta de ese conocimiento.

Daniel Devoto nos dice en un escrito que sobre el fondo español cubano y africano, la Argentina "ha obtenido con el tango la única expresión musical latinoamericana cuyo renombre cubre el globo y que a través de Europa ha llegado al Japón"9. Fondo español sí, hacía ya cuatrocientos años que los españoles estaban en la región. Cubano? coinciden en el mismo continente, pero otras razones? La conexión entre el puerto de La Habana y Buenos Aires. Ellos nos acercan las últimas versiones de Habaneras que España había recreado de las contradanzas europeas. Africanos? Argentina tenía algunos africanos que los tratantes traían por el desolado puerto de Buenos Aires y luego hacía llegar -al igual que el que luego se llamaría Uruguay- a la costa del Pacífico o al lejano Brasil. Una parte de esos 'esclavos' terminaron quedando en el país. Y resulta que fueron escogiendo dos tareas en las que destacaban: panaderos, y... músicos enseñados por sacerdotes o profesores europeos. Destacados en el uso de instrumentos europeos y leyendo música europea religiosa y seglar.

Cuando a fin del siglo XIX, faltos de mano de obra (los suburbios fueron arrasados por fiebre amarilla y tifus, en esos barrios vivían los criollos muy pobres o los negros que quedaban en las costas del Riachuelo contaminado en su totalidad por las industrias de los saladeros) la clase 'patricia' rechaza a la población criolla que queda por ser 'inepta, vaga y mal entretenida' y se decide a traer masivamente inmigración en general europea, de una forma descontrolada.

En una situación desgraciada y caótica, la gente busca en la música y el baile el bálsamo para las tristezas de la vida. Y en el teatro que era lo que la tradición española prefería. La Zarzuela, el Género chico español va a dar origen al Sainete. Ya en los últimos años del siglo donde la música criolla y la milonga se habían hecho escuchar, comienza a adueñarse de la escena ese híbrido fruto de una sociedad mestiza: El Tango.

Poner en escena una obra de teatro, traer o armar compañías para mostrar esas obras, pagar un teatro... todo eso no es barato. Nadie lo hace ofendiendo a su público con músicas, bailes y letras prostibularias.

Sostuve, y lo sigo haciendo que las crisis son (pueden ser) creativas. Y ese país mezcla, y esa sociedad mestiza tuvo que buscar en su desgracia, la forma de sobrevivir.

Dijo Horacio Ferrer "Uno es porque los otros lo han querido, porque ha sido confortado y entendido, esperado y despedido con amor". ${ }^{10}$

Hay dos posibilidades claras para tomar posición: la ortodoxia y la heterodoxia. Desde la ortodoxia definida como aquella posición que cumple normas tradicionales y gene- 
ralizadas o que sigue fielmente o está conforme con los principios de una doctrina, una tendencia o una ideología estamos vegetando en nuestra 'zona de confort'. El término heterodoxia, hace referencia a la cualidad del heterodoxo o disconforme con el dogma de una religión, o economía, aquel que elige la doctrina u opinión que no está de acuerdo con la sustentada por la mayor parte de un grupo. Si esto es así, los argentinos, mezcla híbrida 'crece' con los problemas, con las crisis... siempre y cuando pueda manifestarse.

En la durísima época del 1970-1980 (que ya había comenzado en 1955) donde con la 'razón' de 30.000 muertos y desaparecidos todo se prohíbe, el tango igual que todas las manifestaciones artísticas en Argentina se desvanecen entre censuras y prohibiciones, situación que igualmente sufre Uruguay. Cuando los 'ortodoxos' del tango auguran una vez más que 'el tango ha muerto' Horacio Ferrer se anota en nuestras filas, diciendo: "Pero el doloroso destierro de notables pensadores, escritores y artistas argentinos y uruguayos goza de una inesperada y luminosa consecuencia: los conceptos del tango, su historia y sus cultores ganan en el mundo, nivel universitario para ser atractivo tema de meditación y discusión en sus implicaciones sociales, éticas y políticas." ${ }^{11}$

La pureza, la ortodoxia, no es fructífera. La mezcla, la heterodoxia sí lo es. Lo dicen mis abuelos italianos y españoles y las miles de mezclas posibles que fundaron mi país argentino.

Claro que lo dice mejor, pero es lo mismo, José Saramago: "Que tire la primera piedra quien nunca haya tenido manchas de emigración en su árbol genealógico... si tu no emigraste emigró tu padre, y si tu padre no necesitó mudar de sitio fue porque tu abuelo, antes, no tuvo otro remedio que ir cargando la vida sobre la espalda, en busca de la comida que la propia tierra le negaba."12

\section{Antecedentes y futuro del Tango}

Gracias al éxito europeo a principios del siglo XX, escribe Xavier Febres a principios del XXI, "el tango penetró finalmente en los salones porteños de la clase media, en el amplio público del país de origen, permitiendo así la expansión de su medio de cultivo y la posibilidad de renovación"..13

Claudio Segovia y Héctor Orézzoli con excelentes músicos y parejas de baile en 1983, montan en París un espectáculo teatral Tango Argentino que recorrió y triunfó durante más de 10 años con un tango tan vivo y cambiante como siempre lo había sido.

Nos hallamos claramente, en esos 'saltos generacionales' que sólo pueden permitirse las músicas que disponen en cada momento de una masa crítica de seguidores, de practicantes, así como de una proyección internacional que genera milongas de tango cada día de la semana.

Pero no sólo es, en este caso, la reacción individual, popular, sino también institucional la que encontramos como antecedentes a su declaración como Patrimonio Universal. En 1990 por ley nacional se creó la Academia Nacional del Tango. Pero lo más importante a nivel estatal durante la década fue la sanción de la ley nacional de patrimonialización del tango en 1996 y en 1998 ley de la ciudad de Buenos Aires, que llevaron a la creación 
en 1999 del Festival Buenos Aires Tango y la señal radial FM La 2x4 Tango. Algo sucedía que llevó -quizá por primera vez en su historia- a que el tango contó con apoyo político e institucional.

La gran ruptura que la dictadura militar llevó adelante, quizá quiso ser enmendada por esfuerzos de solidaridad entre la gente y apoyo para recomponer las amenazas del neoliberalismo. Un gran esfuerzo sin duda. Pero en poco tiempo, 23 de febrero de 1995, el diario "Le Monde" desde Europa, titulaba un reportaje a toda página: "En Argentina la juventud se reapropia del tango".

El Gobierno de la Ciudad de Buenos Aires, propagandiza así su creación: La 2x4, Radio de Tango: "La 2x4 es parte del Sistema de Medios Públicos de la Ciudad Autónoma de Buenos Aires. Es la gran Radio de Tango que transmite para todo el mundo las 24 horas del día. Su programación resume el espíritu de nuestra música ciudadana." ${ }^{14}$

Para que el desarrollo sostenible se alcance, que la cultura sostenible sea una realidad, no podemos esperar que sea un proceso que funcione 'automáticamente'. Se necesitan estructuras político-administrativas con capacidad para plantearse procesos, estructuras, mecanismos y sistemas políticos y administrativos para llevar adelante planes ya planteados desde correctas perspectivas de desarrollo.

Pero además no es conseguir que la Unesco declare. Es necesario plantearse con claridad qué hacer, y desde la sociedad civil involucrarse y acceder y participar en las políticas y la toma de decisiones. Una de las características intrínsecas de la cultura es que involucra a una gran variedad de agentes -debe hacerlo-, participación de base amplia para sacar adelante políticas y medidas útiles y efectivas que cumplan las necesidades de las personas y comunidades para las que están destinados.

Algunos años antes (2005) de la declaración de la Unesco, por un incendio en un salón de baile, en Buenos Aires se cerraron muchos salones por seguridad, pero también muchas milongas (salones donde sólo se baila tango). Las características de uno y otros son diferentes, pero la Administración cargó con todo, por las dudas. Tuvieron que asociarse los 'tangueros', mostrarse en la vía pública, negociar con la Administración, etc, para conseguir ser tenidos en cuenta con sus características.

Ya para el año 2006 se sabía que el tango era la principal industria cultural de la ciudad. Desde el Gobierno de la ciudad se organizan Campeonatos de tango, Festivales de tango (que ya van a cumplir 20 años). Todo esto se realiza en bares, clubes, milongas y los encuentros finales en el Club Obras Sanitarias y en el Luna Park. La entrada a muchos de estos eventos es libre, porque moviliza a tanta gente, en general turistas extranjeros que 'revolucionan la ciudad', como dirá su Intendente.

"El tango está revolucionando la Ciudad, porque hay barrios que estaban postergados y se están levantando de la mano de nuestra música popular. Tenemos que hacer que todos en el mundo sepan que la meca, la ciudad a la que hay que ir, es Buenos Aires. (Declaraciones del Jefe de gobierno porteño, Mauricio Macri, publicadas en el diario Clarín, el día 29 de mayo de 2008, sección La Ciudad, pág. 37)

Díaz Marchi, nos encabeza su trabajo con la nota del Intendente de Buenos Aires en 2008 que hemos transcripto. Desde la institución política se tienen en cuenta, en ese momento, tres estrategias consideradas prioritarias en Turismo y Cultura como motor de desarrollo: - Tango: donde contar con especialistas del tema es fundamental. El tango es música, es 
poesía, y es danza. Pero hay que saber situarlo en su historia, en la sociedad que lo generó, que lo volvió a concebir según sus momentos, que lo acompañó al exilio y lo mantuvo en la Patria. Se han ido creando conservatorios, universidades, para dar solidez y seriedad al estudio de este increíble patrimonio que hemos heredado de nuestros antepasados y queremos mantener en el presente y orientar al futuro.

En estos últimos 30 o 40 años se ha tomado muy en serio el estudio de la cultura popular, a encontrar la metodología y las técnicas que se deben emplear en la investigación, la enseñanza y la educación, teniendo especialmente en vista las aplicaciones de la psicología y sociología que usa, aplica, la pedagogía contemporánea.

- Edificios: Refacción de fachadas y reconstrucción y arreglo de casas tradicionales, para su uso en hoteles, salas de comida, baile y tiendas.

- Espectáculos nocturnos: Casas de comida y espectáculos, Milongas (baile de tango), conciertos, etc.

Estos espectáculos son los más elegidos por los turistas y las empresas que los traen. La estudiosa Marta Savigliano (2000) nos informa de una manera muy cuidadosa en qué consisten esas Milongas:

Las milongas, como lugares de placer, son vistas como experiencias democráticas, hasta revolucionarias, que permiten la disolución de las diferencias de edad y de clase, su explosión, en una combinación también de las diferencias masculino y femenino, en el abandono del auto-interés en nombre de un objetivo común más alto que es mantener al tango vivo, reafirmando la capacidad de producir una forma cultural local.

Será porque soy argentina o porque amo el tango, pero no puedo terminar sin dos hermosas frases:

El tango es una posibilidad infinita (Leopoldo Marechal)

Y de Eladia Blázquez, increíble tanguera cuatro versos de su "Honrar la vida":

Merecer la vida es erguirse vertical, más allá del mal, de las caídas...

Porque no es lo mismo que vivir...

¡Honrar la vida!

\section{Conclusiones}

En 1890 en el Teatro de José Podestá, el famoso payaso Pepino el 88, barría y cantaba: La basura que se barre / no deja de ser basura / aunque a los aires se suba / basura será en el aire. La basura ya era entonces la corrupción, la especulación, los negociados. 
Diez años después Ángel Villoldo, refiriéndose a la falta de respeto de su mundo, llama a uno de sus primeros tangos: Bazar de la Mescolanza: "Había preciosas telas / de gró, de seda y fular/ tijeras para esquilar, / lámparas calentadores / cintas de todos los colores / alpargatas uruguayas / queso gruyer, pantallas, / calzoncillos, bicicletas, / jabón de coco, galletas, / papas, relojes y mallas...".

Y va a ser en la gran crisis mundial d 1929, cuando la 'gran mescolanza', en manos del gran Discépolo, se llame Cambalache, dirá: "Que el mundo fue y será una porquería, ya lo sé... / en el quinientos seis y en el dos mil también... / que siempre ha habido chorros, maquiavelos y estafaos / valores y doblez... ".

Ya hace tiempo que considero que el enfoque histórico (los paradigmas) son diferentes según lo que se esté estudiando: en mi caso, un hecho musical fruto de un sector popular de la sociedad, tendrá que tener en cuenta cómo vive la gente, condiciones de trabajo, en qué se divierte u ocupa su ocio, etc. La Dra. Dolores Juliano, Universidad de Valencia, afirmaba en sus clases que en el Siglo XVI sabían que las brujas hacen pactos con el diablo, en el 17 y 18 que la esclavitud está basada en la voluntad divina y en el orden natural de las cosas. Y prácticamente en toda la historia que la mujer es naturalmente inferior, que hay una sola religión (la nuestra) y que nuestra forma de organizar la familia es la correcta, única, lógica y natural (en Argentina durante una mala época se decía que si alguien desaparecía "Algo habría hecho").

Honestamente, nos refugiamos en discursos construidos. Cómo y porqué se construyen estas categorías estigmatizadoras, sus paradigmas de comprensión histórica: Porque nos han enseñado desde siempre que lo nuevo, lo que se mueve, lo que cambia, lo distinto, ES malo. Debemos tenerle miedo. Si se dan cambios y se dan siempre, todos los implicados cambian. Cuando el tango es criticado desde la cultura imperante, está también él obligando a cambiar a esas elites culturales juzgadoras.

La historia no está hecha de una vez y para siempre. Cada momento recupera, valora lo que necesita o elige. El pensamiento holístico asegura que el Todo es mucho más que la suma de las Partes, y si al unirlo tenemos en cuenta la educación, la cultura, el resultado mejora.

\section{Notas}

1. Borges, Jorge Luis, 1965, Para las seis cuerdas. Buenos Aires, Argentina. Emecé Editores. (Milonga de los orientales, pág.46)

2. Redacción. 2009, 20 de enero, El Tango Patrimonio de la Humanidad. La Nación, Periódico Argentina. Recuperado de https://www.lanacion.com.ar/cultura/el-tango-patrimonio-de-la-humanidad-nid1091770

3. Redacción, 2009, 30 de septiembre. El tango, patrimonio de la Humanidad. BBC Mundo. Recuperado de https://www.bbc.com/mundo/america_latina/2009/09/090930_1232_ tango_patrimonio_gtg

4. Redacción, 2009, 30 de septiembre. Declaración oficial de la Unesco: Presentación de Buenos Aires y Montevideo en los Emiratos Árabes: El tango ya es Patrimonio Cultural 
de la Humanidad. El tango ya es Patrimonio Cultural de la Humanidad. Clarín. Recuperado de: https://www.clarin.com/ediciones-anteriores/tango-patrimonio-cultural-humanidad_0_H1ItK_RTtx.html

- Redacción, 2009, 30 de septiembre: Orgullo Argentino. El tango fue declarado patrimonio de la humanidad. Página 12. Recuperado de: https://www.pagina12.com.ar/diario/ ultimas/20-132657-2009-09-30.html

- Redacción, 2009, 30 de septiembre. El tango es Patrimonio Cultural de la Humanidad. Perfil. Recuperado de: https://www.perfil.com/noticias/cultura/-20090930-0009.phtml

- Redacción, 2009, 30 de septiembre. La Unesco declaró al tango como patrimonio cultural inmaterial de la humanidad. La Capital de Mar del Plata. Recuperado de: http://www. lacapitalmdp.com/noticias/Espectaculos/2009/09/30/122455.htm

5. Moreno, J. (2019). Patrimonio Unesco: Tango, patrimonio inmaterial de la humanidad. El Souvenir de México. Recuperado de: https://elsouvenir.com/tango-patrimonio-inmaterial-de-la-humanidad/

6. Kokubu, J. M. (2017) "Algunas claves epistemológicas de la vigencia y proyección del tango", Participación en la mesa: Tango, Cultura e Identidad, del II Congreso de la Academia Nacional del Tango: Tango, Cultura e Identidad. Buenos Aires: Ed. Fundación Banco Ciudad 1016. $1^{\circ}$ Edición Julio de 2017.

7. Norese, M. R. (2002) "Contextualización y Análisis del Tango. Sus orígenes hasta la aparición de la Vanguardia" Tomo I, Pág. XV, Salamanca: Edit. Universidad de Salamanca. 8. Maroni, E. (1929). La Humilde Cosecha, donde está su conocida Apología Tanguera, editado en Buenos Aires, en Edición propia. Se puede recuperar este poema en https:// www.todotango.com/musica/tema/1793/Apologia-del-tango/

9. Devoto, D. (1977). "Expresiones musicales, sus relaciones y alcances en las clases sociales", pág. 31, En "América Latina en su música", relatora Isabel Aretz. México, Ed. Siglo Veintiuno Editores.

10 y 11. "Festival Internacional de Tango Granada, 25 años, memoria coral." Horacio Rébora. (10) Portada de Horacio Ferrer, (11) pág. 9, El Festival Internacional de Tango en granada: Luz Precursora. Edit. Universidad de Granada.

12. Saramago, J. ( 2009). "Historias de la emigración". en Otros Cuadernos de Saramago. Recuperado en: https://www.buenosaires.gob.ar/la2x4.

13. Febrés, X., 2003, 22 de enero. El tango también sale del corralito. La Vanguardia. Recuperado en: http://hemeroteca.lavanguardia.com/preview/2003/01/22/pagina-29/34014990/pdf.html?search=tango

14. Díaz Marchi, D. (2008) Tango, Recurso Cultural estratégico, pág. 3, trabajo presentado en las V Jornadas de Sociología de la UNLP, Buenos Aires. Recuperado en: https:// www.google.es/search?sxsrf=ACYBGNQTJmDAL4h1iWHD99lvOgTRoYDhAQ\%3A15 81187090966\&source $=$ hp\&ei=EgA_XqabOISCapaFmCA\&q=Tango+Recurso+Cultural + estrategico $\% 2 \mathrm{C}+$ Daniela+diaz+Marchi\&oq=Tango+Recurso+Cultural+estrategico $\% 2 \mathrm{C}$ +Daniela+diaz+Marchi\&gs_l=psyab.3..33i16014.1033.30295..32304...2.0..0.224.6079.18j3 8j1.............gwswiz.......0i131j0j0i3j0i10j0i22i30j33i21j33i22i29i30.qh1c9lrs19Y\&ved=0a hUKEwim7IL3zMLnAhUEgRoKHZYCBgQQ4dUDCAg\&uact=5 


\section{Referencias Bibliográficas}

Borges, Jorge Luis. (1965). Para las seis cuerdas. Buenos Aires: Emecé Editores.

Devoto, D., (1977) Expresiones musicales, sus relaciones y alcances en las clases sociales, pág. 31, En "América Latina en su música", relatora Isabel Aretz. México: Siglo Veintiuno Editores.

Kokubu, J. M.(2017). Algunas claves epistemológicas de la vigencia y proyección del tango, Participación en la mesa: Tango, Cultura e Identidad, del II Congreso de la Academia Nacional del Tango: Tango, Cultura e Identidad. Buenos Aires: Fundación Banco Ciudad 1016. $1^{\circ}$ Edición Julio de 2017.

Norese, M. R. (2002). Contextualización y Análisis del Tango. Sus orígenes hasta la aparición de la Vanguardia" Tomo I, Pág. XV, Salamanca: Universidad de Salamanca.

\section{Páginas Web}

Díaz Marchi, D. (2008) Tango, Recurso Cultural estratégico, pág. 3, trabajo presentado en las V Jornadas de Sociología de la UNLP, Buenos Aires. Recuperado en: https://www. google.es/search?sxsrf=ACYBGNQTJmDAL4h1iWHD99lvOgTRoYDhAQ\%3A15811 87090966\&source=hp\&ei=EgA_XqabOISCapaFmCA\&q=Tango+Recurso+Cultural+e strategico\%2C+Daniela+diaz+Marchi\&oq=Tango+Recurso+Cultural+estrategico\%2C +Daniela+diaz+Marchi\&gs_l=psyab.3..33i16014.1033.30295..32304...2.0..0.224.6079.18 j38j1.............gwswiz.......0i131j0j0i3j0i10j0i22i30j33i21j33i22i29i30.qh1c9lrs19Y\&ved $=0$ ahUKEwim7IL3zMLnAhUEgRoKHZYCBgQQ4dUDCAg\&uact $=5$

Febrés, X., 2003, 22 de enero. El tango también sale del corralito. La Vanguardia. Recuperado en: http://hemeroteca.lavanguardia.com/preview/2003/01/22/pagina-29/34014990/pdf. html?search=tango

Maroni, E. (1929). La Humilde Cosecha, donde está su conocida Apología Tanguera, editado en Buenos Aires, en Edición propia. Se puede recuperar este poema en https://www. todotango.com/musica/tema/1793/Apologia-del-tango/

Moreno, J. 2019. Patrimonio Unesco: Tango, patrimonio inmaterial de la humanidad. El Souvenir de México. Recuperado de: https://elsouvenir.com/tango-patrimonioinmaterial-de-la-humanidad/

Redacción. 2009, 20 de enero, El Tango Patrimonio de la Humanidad. La Nación, Periódico Argentina. Recuperado de https://www.lanacion.com.ar/cultura/el-tango-patrimoniode-la-humanidad-nid1091770

Redacción, 2009, 30 de septiembre. El tango, patrimonio de la Humanidad. BBC Mundo. Recuperado de https://www.bbc.com/mundo/america_latina/2009/09/090930_1232_tango_patrimonio_gtg

Redacción, 2009, 30 de septiembre. Declaración oficial de la Unesco: Presentación de Buenos Aires y Montevideo en los Emiratos Árabes: El tango ya es Patrimonio Cultural de la Humanidad. El tango ya es Patrimonio Cultural de la Humanidad. Clarín. Recu- 
perado de: https://www.clarin.com/ediciones-anteriores/tango-patrimonio-culturalhumanidad_0_H1ItK_RTtx.html

Redacción, 2009, 30 de septiembre: Orgullo Argentino. El tango fue declarado patrimonio de la humanidad. Página 12. Recuperado de : https://www.pagina12.com.ar/diario/ ultimas/20-132657-2009-09-30.html

Redacción, 2009, 30 de septiembre. El tango es Patrimonio Cultural de la Humanidad. Perfil. Recuperado de: https://www.perfil.com/noticias/cultura/-20090930-0009.phtml

Redacción, 2009, 30 de septiembre. La Unesco declaró al tango como patrimonio cultural inmaterial de la humanidad. La Capital de Mar del Plata. Recuperado de: http://www. lacapitalmdp.com/noticias/Espectaculos/2009/09/30/122455.htm

Saramago, J. (2009). "Historias de la emigración". en Otros Cuadernos de Saramago. Recuperado en: https://www.buenosaires.gob.ar/la2x4.

Abstract: Cultural sustainability. Tango is already between 130 and 140 years old since its creation by 'the poor people of the Montevidean and Buenos Aires conventillos, who were the inventors of tango. "The hybridity of that town - infinite mixtures of external and internal immigration - drives it to react in the face of the crises and the blows of life, it creates a dynamic, develops a skill and achieves (at least always tries) "that the crises be creative." Argentina had since the 19th century free secular education for all. being hungry or having difficulties but having a people with intelligence and creativity, that's why tango arises and lives and survives, it's not always the same tango: reality changes, people change, happiness and pain change, but there's always an answer ... and therefore a rebirth. Able to invent a language: lunfardo, and a music: Tango. Mestizo and heterodox people, who grow with crises, expressing themselves with their culture.

Keywords: Tango - immigration end nineteenth century - reborn tango 1990 - lunfardo milongas - Intangible Cultural Heritage - orthodoxy-heterodoxy.

Resumo: Sustentabilidade cultural. O tango já tem entre 130 e 140 anos desde a sua criação pelos 'pobres dos conventillos de Montevidéu e Buenos Aires, que foram os inventores do tango. "O hibridismo daquela cidade - infinitas misturas de imigração externa e interna - leva a reagir diante das crises e dos golpes da vida, cria uma dinâmica, desenvolve uma habilidade e consegue (pelo menos sempre tenta) "que as crises sejam criativas". A Argentina tinha desde o século XIX educação secular gratuita para todos. estar com fome ou ter dificuldades, mas ter um povo com inteligência e criatividade, é por isso que o tango surge, vive e sobrevive, nem sempre é o mesmo: mudanças na realidade, pessoas mudam, felicidade e dor, mas sempre há uma resposta... e, portanto, um renascimento, capaz de inventar uma linguagem: lunfardo e uma música: tango, mestiços e heterodoxos, que crescem em crise, se expressando com sua cultura. 
Palavras chave: Tango - imigração final do século XIX - renascer tango 1990 - lunfardo milongas - Patrimônio Cultural Imaterial - ortodoxia-heterodoxia.

[Las traducciones de los abstracts fueron supervisadas por el autor de cada artículo] 